\title{
Open business model innovation: Literature review and agenda for future research
}

\section{Tiare-Maria Brasseur}

Lecturer, Department of e-Business

University of Vienna

Address: 1, Oskar-Morgenstern-Platz, Vienna, 1090, Austria

E-mail: tiare.brasseur@gmail.com

\section{Andreas Mladenow}

Lecturer, Department of e-Business

University of Vienna

Address: 1, Oskar-Morgenstern-Platz, Vienna, 1090, Austria

E-mail: andreas.mladenow@univie.ac.at

\section{Christine Strauss}

Professor, Department of e-Business

University of Vienna

Address: 1, Oskar-Morgenstern-Platz, Vienna, 1090, Austria

E-mail: christine.strauss@univie.ac.at

\begin{abstract}
In today's fast-paced business environment, firms are constantly pressured to innovate in order to remain competitive. Business model innovation (BMI) has recently attracted increasing attention as a promising approach to achieve competitive advantage in the face of fierce competition. Despite its great potential, however, BMI also entails high degrees of complexity, uncertainty and financial risk. Fueled by the rise of digital technologies, BMI has become increasingly open and collaborative in the recent past.

The aim of this paper is to investigate the role and implications of open and collaborative practices in BMI and to provide a comprehensive review of available literature in this field. Therefore, a systematic review of literature at the intersection of Open Innovation (OI) and BMI has been carried out. Our analysis of the literature identified two major research streams in open business model innovation (OBMI): OBMI trends (customer-driven BMI, BM co-creation, early BM validation, virtual collaboration, design thinking) and OBMI effects. Overall, the findings support a growing trend of collaboration and co-creation in BMI supported by digital or tangible tools, and further reveal that OI has a direct positive effect on BMI success. Analysis of the literature also shows that the field of OBMI is still an under-researched area.
\end{abstract}


Key words: business model innovation, open business model innovation, digital business modeling, open innovation, collaboration, collaborative infrastructure, co-creation, customer innovation.

Citation: Brasseur T.-M., Mladenow A., Strauss C. (2017) Open business model innovation: Literature review and agenda for future research. Business Informatics, no. 4 (42), pp. 7-16. DOI: $10.17323 / 1998-0663.2017 .4 .7 .16$.

\section{Introduction}

$\mathrm{I}$ t was not so long ago that in real world scenarios "innovation" implied higher investments in internal research and development (R\&D) than the competitors [1]. More recent and enhanced innovation strategies rely on collaborative approaches with external partners to complement their innovative capabilities. Chesbrough first introduced the notion of open innovation (OI) as a mode of innovation in which firms use external knowledge sources and external markets to accelerate internal innovation [1]. OI has received increasing attention from researchers [1-10] and the media in the recent past. The consensus view among OI scholars is that the value of reusing the same knowledge over and over again is limited and can harm a firm's ability to innovate $[1,2,7]$. Therefore, the OI model encourages firms to open up their processes to the outside world and allow a more participatory and decentralized approach to innovation in contrast to the previously dominant model of "closed innovation" [1]. The notion of OI overlaps with numerous other concepts such as open source, crowdsourcing, co-creation, user innovation and other forms of distributed innovation [11].

OI helps firms to access a wider array of talent and skills, to reduce cost of $R \& D$, to gain additional revenue sources (through licensing, joint ventures, etc.) and to reduce the time-to-market for new products [12-14]. By combining internal and external sources of innovation, firms gain access to new innovations, new customers, new ways of commercialization and additional markets $[12,13]$. In practice, firms such as Lego, 3M, P\&G, IBM and Dell have demonstrated the power of OI to improve innovation and financial performance.

Besides OI, BMI has emerged as a promising approach to break out of fierce competition, particularly in face of the (higher) imitability of products and processes $[15,16]$. It has been argued in the literature that business models (BMs) have become the new basis of competition [17] and probably the most challenging type of innovation. When trying to develop a new BM, firms are confronted with high levels of uncertainty, ambiguity and complexity [18]. A change in the BM can mean multi-billions in profits or it can mean corporate failure [19]. The high risk associated with BMI hence resides in the large scope of business transformation when BMI occurs. At the same time, however, BMI is increasingly recognized as a key driver of super normal profits and the main source of sustainable competitive advantage $[1,20]$. In this context, a systematic literature review has been conducted in five leading scientific databases (ACM, EBSCO, IEEE, Springer Link, Wiley) to provide a comprehensive overview of available literature on BMI to identify the major topics and concepts discussed in this field.

\section{OBMI trends and effects}

Analysis of the literature identified two major new research streams in OBMI: OBMI trends and OBMI effects. In the available literature, various approaches and toolkits have been discussed, ranging from theoretical models, to (open) software solutions for virtual collabo- 
ration and playful design thinking methods to advance BMI. Furthermore, five emerging trends in OBMI have been identified. Overall, the literature showed a trend of more collaborative forms of BMI and suggested the use of different approaches and tools to integrate outside partners in OBMI activities, as depicted in Table 1.

Envisaging the participation of supply chain members in OBMI activities, all studies involve customers in the BMI process. This is not surprising, as the keywords used for the systematic literature search aimed to identify articles exploring target group involvement, i.e. the participation of customers, in OBMI practices [2]. Moreover, 5 out of 11 publications choose to collaborate with both - customers and suppliers - to advance BMI. Additionally, a single study chose to involve customers, suppliers and a research institution in a collaborative setting of OBMI [21].

Envisaging the intensity of supply chain partner participation in OBMI activities, the International Association for Public Participation [22] has developed a stakeholder participation spectrum to demonstrate the possible types (i.e. levels) of stakeholder participation. Based on this spectrum, two participation approaches dominate the literature on OBMI: "involvement" and "collaboration". The majority of available publications, i.e. 7 out of 11 articles, choose a collaboration approach which allowed supply chain members to actively contribute new BM ideas. On the other hand, two publications pursued an involvement approach, which included adding to, modifying, or recombining knowledge contributed by supply chain partners.

\section{BM co-creation}

The topic of BM co-creation is most frequently discussed among available literature on OBMI [23-26]. Ebel et al. define BM cocreation as the activity of "developing busi- ness models together with customers in a collaborative manner" [24]. In other words, BM co-creation encourages the active participation of supply chain partners in the creation of new BM. Furthermore, co-innovation describes a new innovation paradigm, which incorporates collaboration and co-creation in a platform approach [26]. Accordingly, coinnovation emphasizes on the co-creation of unique value and experience with external stakeholders, rather than merely creating value for them.

The literature analysis we performed revealed that opening up the BMI process to allow BM co-creation enables new business opportunities [27] and enhances the quality of the developed BMs [24]. It has been argued that by seeking external feedback and collaborating with customers to share BMs, firms can test the commercial viability of a new BM before implementing it [23, 24]. Particularly, the role of customers and suppliers as valuable participants in the BMI process has been highlighted in the literature. Ogilvie [25] argues that engaging directly with customers and prospective partners helps to co-create solutions that deliver value to all stakeholders involved. Buur and Gudiksen [21] arrive at the conclusion that the "discussion of business models within the company, and with suppliers and customers is necessary to ensure competitive edge". Similarly, Ebel et al. [24] denote target group involvement as crucial for successful BMI. Looking at co-creation from a customer-perspective, Ogilvie claims that customers embraced the invitation to participate in BM co-creation sessions and were enthusiastic about the idea to co-create a new solution [25].

Furthermore, Chew put forward the view that "service innovation and business model innovation are the source for business growth" [23]. The author introduces the prototype of a new integrated design method, the so-called iSIM (integrated service innova- 
Literature analysis

\begin{tabular}{|c|c|c|c|c|c|c|c|c|c|c|}
\hline \multirow[b]{2}{*}{ Source } & \multicolumn{5}{|c|}{ OBMI Trends } & \multirow[b]{2}{*}{ 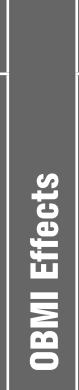 } & \multicolumn{4}{|r|}{ Toolkits } \\
\hline & 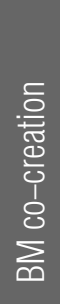 & 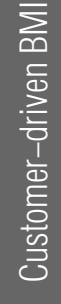 & 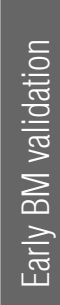 & 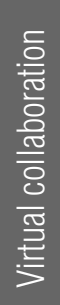 & 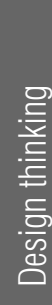 & & 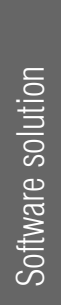 & 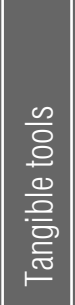 & 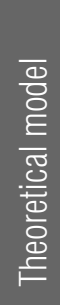 & Additional Information \\
\hline $\begin{array}{l}\text { Berre et al. } \\
\text { (2013) [27] }\end{array}$ & $x$ & & $x$ & $x$ & & & X & & & $\begin{array}{l}\text { - Cloud-based platform for OBMI } \\
\text { - Pilot testing of business operations platforms } \\
\text { - Social media based innovation community }\end{array}$ \\
\hline $\begin{array}{l}\text { Buur and } \\
\text { Gudiksen } \\
\text { (2012) [21] }\end{array}$ & $x$ & $x$ & & & $X$ & & & $x$ & & $\begin{array}{l}\text { - BM design experiments with "tangible" BMs } \\
\text { - Interactive pinball design (gamification) } \\
\text { - Customer-side of the BM }\end{array}$ \\
\hline $\begin{array}{c}\text { Chew } \\
\text { (2015) [23] }\end{array}$ & $x$ & $x$ & $X$ & $x$ & & & $x$ & & $x$ & $\begin{array}{l}\text { - Integrated service innovation method (iSIM) model } \\
\text { for simultaneous service innovation \& BMI } \\
\text { - Customer co-created value (user value) } \\
\text { - "Backward" BM design (customer as start) }\end{array}$ \\
\hline $\begin{array}{l}\text { Denicolai et al. } \\
\text { (2014) [33] }\end{array}$ & & & & & & $x$ & & & & $\begin{array}{l}\text { - Effects of external knowledge sourcing on firm } \\
\text { growth (as proxy for BMI success) } \\
\text { - Annual report analysis ( } 310 \text { European firms) }\end{array}$ \\
\hline $\begin{array}{l}\text { Ebel et al. } \\
\text { (2016) [24] }\end{array}$ & $x$ & $x$ & $x$ & $x$ & & & $x$ & & $x$ & $\begin{array}{l}\text { - Pilot testing of business model development tool } \\
\text { with test users } \\
\text { - Based on online collaboration literature } \\
\text { - Target group / expert / stakeholder integration }\end{array}$ \\
\hline $\begin{array}{l}\text { Gudiksen } \\
\text { (2015) [32] }\end{array}$ & $x$ & & & & $x$ & & & $x$ & & $\begin{array}{l}\text { - Playful BM design experiments (gamification) } \\
\text { - Role plays, use of tangible resources } \\
\text { - Participatory innovation }\end{array}$ \\
\hline $\begin{array}{l}\text { Huang et al. } \\
\text { (2013) [13] }\end{array}$ & & & & & & $x$ & & & $x$ & $\begin{array}{l}\text { - Effects of OI on BMI \& organisational inertia } \\
\text { - Effects of BMI on firm performance } \\
\text { - Study among } 141 \text { small and medium enterprises } \\
\text { (in Taiwan) }\end{array}$ \\
\hline $\begin{array}{c}\text { Ogilvie } \\
(2015)[25]\end{array}$ & $x$ & & $x$ & & $x$ & & & $x$ & $x$ & $\begin{array}{l}\text { - BM co-creation (customers \& industry partners) } \\
\text { - Early BM \& revenue model validation } \\
\text { - 5Bs template, BM prototypes (mock-ups) }\end{array}$ \\
\hline $\begin{array}{c}\text { Pynnönen et al. } \\
\text { (2012) [29] }\end{array}$ & & $x$ & $x$ & $x$ & & & $x$ & & $x$ & $\begin{array}{l}\text { - Managing customer-driven BMs } \\
\text { - Customer participation in BMI, BM validation } \\
\text { - Social media based innovation community }\end{array}$ \\
\hline $\begin{array}{l}\text { Trimi et al. } \\
\text { (2012) [26] }\end{array}$ & & $x$ & $x$ & & & & & & $x$ & $\begin{array}{l}\text { - BM experimentation \& BM flexibility } \\
\text { - Customer development process (validation) } \\
\text { - Lean philosophy (testing of BM hypotheses) }\end{array}$ \\
\hline $\begin{array}{l}\text { Zolnowski et al. } \\
\text { (2014) [28] }\end{array}$ & $x$ & $x$ & & & & & & & $x$ & $\begin{array}{l}\text { - Customer as start of (new) BM design } \\
\text { - Customer impact on other BM dimensions } \\
\text { - BM canvas (firm / customer / partner perspective) }\end{array}$ \\
\hline
\end{tabular}


tion method), for simultaneous service innovation and BM design. The model is based on the assumption that customer value cocreation is central to BMI. Thus, the iSIM model facilitates the engagement of customers as co-producers of value. A co-creation approach in BMI enhances the mutual value proposition alignment between the customer-side and the supply-side business ecosystem [23, 28]. Similarly, Ebel et al. recommend the discussion and refinement of new BM alternatives with customers and suppliers until mutual agreement among all stakeholders is reached [24].

To practice co-creation, it has been proposed that firms need an organizational culture of "open leadership" and "organizational learning" [23]. With the use of rapid BM experimentation, firms can test the commercial viability of new BM concepts before committing capital on the design and implementation of the BM [23]. Ebel et al. point to a certain flexibility in terms of BM resources and capabilities "to ensure that the business models can be adapted to changing market situations" [24]. Zolnowski et al. stress the importance of adopting a "value network logic" instead of focusing on a single value chain, to foster the integration of and interaction with external partners [28]. Furthermore, Chew emphasized a combination of resource integration and configuration capabilities to be able to leverage externally generated knowledge for internal processes, i.e. socalled "absorptive capacity" [23].

\section{Customer-driven BMI}

Another aspect is the need for a more "customer-centered model” of BMI [26]. Pynnönen et al. argue that "firms do not necessarily know what the value preferences of their customers are" [29], so they should recognize customers as valuable participants in various roles in the BMI process. Zolnowski et al. take the customer as the "starting point" of BMI by positioning the customer at the top of the BM [28]. Visualising all potential interaction points with the customer helps to identify how the customer co-determines and influences other BM dimensions [28]. Chew proposes to first envision what the unique customer experience should be and then backward design the BM and service offering accordingly [23]. In the same way, Pynnönen et al. introduce a four-stage Business Mapping Framework to analyze the fit between the firm's current BM and customer value [29]. Each BM element was weighted according to customer value preferences to identify the core and non-core components of the $\mathrm{BM}$ and exclude non-value adding elements [29]. Trimi and Berbegal-Mirabent stress the importance of "customer validation" before creation [26]. They seize on the idea of customer development. The main principle of the customer development process is that a new concept or idea, first needs to be validated by customers to be able to proceed to the creation stage, or otherwise pivots back to the discovery stage. Regarding BMI, customer validation includes the verification of $\mathrm{BM}$ elements such as the perceived value of the offering, or the appropriateness of pricing or distribution channels [26]. Finally, Pynnönen et al. point to the importance of continuous involvement of customers in the BMI process to repeatedly align a firm's BM to current and emerging market needs in an iterative manner to obtain the essential realtime information about changing customer preferences [29].

\section{Early BM validation}

Envisaging the topic of early BM validation, researchers agree that "validation before creation", i.e. seeking external feedback and target group involvement in early stages of BM development, is vital to the success of BMI $[24,26]$. Thus, through using an early BM validation approach, firms can test the com- 
mercial viability of a new BM concept before making investments beyond planning [23, 25]. Early BM validation helps firms to reduce the high degrees of uncertainty and risk entailed in BMI. Ogilvie argues that the development of early BM validation techniques is the "key to success" [25]. Thus, through early and ongoing interactions with customers, firms can increase their chances of success [26]. BMs should hence be flexible enough to allow quick iterations and trial-and-error learning from early validation attempts. Particularly for early-stage businesses, the development of experimentation capabilities to rapidly test and validate their business hypotheses is crucial [26]. Ogilvie involves the use of visualization and design thinking techniques in BM co-creation sessions with customers and prospective partners. A telematics provider used visual BM prototypes (i.e. posters) "with just enough information to allow customers to understand how the BM might work", but also leaving enough space for comments and ideas by the workshop participants [25]. This innovative approach allowed the firm to validate and reconfigure a new BM concept together with a revenue model at minimal expense [25].

\section{Virtual collaboration}

Another major OBMI topic identified in the course of the review is "virtual collaboration". Available literature highlights the crucial role of IT tools to support open and collaborative approaches of designing new BMs [24]. In this regard, digital OBMI platforms aim at providing $\mathrm{BM}$ development teams with innovation community support for BMI challenges. The principal idea behind virtual collaboration for BMI is thus very similar to a crowdsourcing approach, which makes use of collective capacities to solve complex problems [30, 31]. The digital business modeling tools presented in the literature support a variety of different features such as voting, evaluations, rating, search and access control, community functions (profile pages, interest groups), messaging, commenting and other collaboration features such as file sharing [23, 24, 27, 29].

\section{Design thinking}

The fifth major topic covered by the literature is design thinking. Design thinking describes different participatory innovation methods involving experimentation, tangible resources and game-like innovation activities to stimulate the creative exploration of innovative solutions [21]. The approach of "tangible business modelling" allowed participants to "express themselves with their hands" [21]. The analyzed literature reported the use of tangible resources such as sticky notes [25] or balls and bricks [32] to facilitate collaboration among (multi-disciplinary) BM co-creation teams. Buur and Gudiksen conducted iterative BM experiments in various interactive settings to trigger new discussions and solution-based thinking. The researchers arrived at the conclusion that "playfully 'thinking with hands and body' enhances 'the quality of conversations' towards an innovative outcome" [21]. Similarly, Gudiksen chose different BM design games for the playful experimentation with new BM ideas [32]. It has been demonstrated that approaching the $\mathrm{BM}$ as a design problem advances new perspectives on BMI initiatives. The use of tangible resources and a randomizer (i.e. a dice) helped to spark new ideas and combinations. Eventually, BM design games have two major benefits: (1) they impose clear rules that had to be followed by all participants, and (2) they provide a joyful and engaging atmosphere, which allowed participants to "step out of the real life" ("foolishness") and enjoy the "freedom to play" and stimulated experiential learning [32]. To successfully practice design thinking for BMI, firms need to create a tempo- 
rary space for imagination and encourage an experimental, game-oriented culture and the freedom to improvise, play and test BM concepts $[21,32]$.

\section{OBMI effects}

Two publications in available literature on OBMI discussed how OI can be effective in creating BMI $[13,33]$. Both studies used a quantitative approach to explore the implications of external knowledge sourcing for BMI and firm performance [13] or firm growth "as a proxy for BMI success" [33], respectively. By using survey research methodologies Huang et al. found that OI can be effective in changing "organisational inertia" and hence create BMI [13]. The notion of organizational inertia describes an organization's difficulty in changing its organizational structure. In addition, organizational inertia has a negative influence on both OI and BMI [13]. Therefore, it is vital to overcome organizational inertia to be able to adapt to fast changing market needs [13]. Furthermore, the researchers have claimed that OI has a direct positive influence on both BMI and firm performance.

By using accounting indicators as a proxy for knowledge acquisitions, Denicolai et al. aim at understanding how internal and external knowledge assets can be combined to contribute to a firm's growth as a proxy for BMI success [33]. For this purpose, scholars investigated the interplay between internally developed knowledge (KINT) and externally acquired knowledge assets (EINT) to create value. Their research identifies an inverted U-shaped tension between the costs and benefits of external knowledge sourcing and internal absorptive capacity [33]. Thus, it has been argued that increasing investments in externally generated knowledge assets has a positive effect on a firm's growth, but only up to a certain point - beyond this threshold it has a negative effect on a firm's growth as the orga- nization encounters difficulties in absorbing such high levels of external knowledge [33]. The researchers arrive at the conclusion that there is an "optimal level" of external knowledge, depending on the absorptive capacity of the firm, at which firm growth, and thus BMI success, is maximized.

\section{Conclusion}

The analysis of literature we presented shows that the field of OBMI is still an underresearched area, as only 11 publications met the inclusion criteria. It was found that available literature discusses various trends as well as the effects of OBMI practices. Analysis of the available literature reveals that OI has a direct positive effect on BMI success. It was found that involving outside partners, particularly customers, in BMI processes may enhance both the quality of developed BMs as well as a firm's performance - at least up to a certain level. Regarding the "openness" of BMI activities, all 11 publications included involve customers in the process of BMI, while some chose to additionally cooperate with suppliers and research institutions to advance BMI. Furthermore, the majority of publications chose a collaborative BMI setting, which allowed outside partners to actively contribute new BM ideas. Furthermore, five major trends in OBMI have been identified.

First, the trend of BM co-creation has been most frequently discussed, indicating the growing importance of collaboration in BMI. Second, the literature analysis revealed the need for a more customer-centric model of BMI. Third, the findings of this review suggest that establishing capabilities to validate new BM concepts in early stages of development is crucial for successful BMI. Therefore, it has been proposed that firms should seek early target group involvement to be able to achieve BM "validation before creation". Fourth, available literature has presented different methods of "virtual col- 
laboration" for BMI. The digital collaboration tools discussed in the literature draw on crowdsourcing methods for BMI challenges and highlight the crucial role of ICT in facilitating OBMI. Fifth, the application of design thinking in BMI represents another key finding of this review. This literature review reveals that approaching the $\mathrm{BM}$ as a design problem through the use of tangible and visual BM "mock-ups" in experimental, game-like innovation activities enhances the quality of discussions among participants and thus increases innovation output. It has been argued that using design thinking methods in OBMI helps firms to advance new perspectives on BM challenges and allows them to both validate and collect new BM ideas at minimal expense.
It can be concluded that OBMI represents an important research area, which is still in its infancy. This paper delivers a comprehensive review of knowledge in this emerging research field. Given the insights on the growing trend of collaboration in BMI, further research will focus on exploring increasingly collaborative approaches in BMI. Additionally, future work might shed light on BM co-creation activities regarding e.g. their application in different stages of the innovation process and the direction of information flows. Furthermore, as virtual collaboration tools and design thinking methods are both expected to play an increasing role in facilitating BMI in the future, they represent promising areas for further research.

\section{References}

1. Chesbrough H. (2010) Business model innovation: Opportunities and barriers. Long Range Planning, vol. 43, no. 2-3, pp. 354-363.

2. Brasseur T.-M., Mladenow A., Strauss C. (2017) Business model innovation to support smart manufacturing. Proceedings of American Conference on Information Systems 2017. Workshop on Smart Manufacturing. Boston, USA, 10-12 August 2017. Available at: http://aisel.aisnet.org/ sigbd2017/9 (accessed 16 October 2017).

3. Enkel E., Gassmann O., Chesbrough H. (2009) Open R\&D and open innovation: Exploring the phenomenon. $R \& D$ Management, vol. 39, no. 4, pp. 311-316.

4. Gassmann O., Enkel E., Chesbrough H. (2010) The future of open innovation. $R \& D$ Management, vol. 40, no. 3, pp. 213-221.

5. Huizingh E.K. (2011) Open innovation: State of the art and future perspectives. Technovation, vol. 31, no. 1, pp. 2-9.

6. Mladenow A., Fröschl K.A. (2011) Kooperative forschung. Frankfurt am Main: Lang.

7. Laursen K., Salter A. (2006) Open for innovation: the role of openness in explaining innovation performance among U.K. manufacturing firms. Strategic Management Journal, vol. 27, no. 2, pp. $131-150$.

8. Lopez-Vega H., Tell F., Vanhaverbeke W. (2016) Where and how to search? Search paths in open innovation. Research Policy, vol. 45, no. 1, pp. 125-136.

9. Prugl R., Schreier M. (2006) Learning from leading-edge customers at The Sims: Opening up the innovation process using toolkits. $R \& D$ Management, vol. 36, no. 3, pp. 237-250.

10. West J., Bogers M. (2014) Leveraging external sources of innovation: a review of research on open innovation. Journal of Product Innovation Management, vol. 31, no. 4, pp. 814-831.

11. Mokter H. (2013) Open innovation: so far and a way forward. World Journal of Science, Technology and Sustainable Development, vol. 10, no. 1, pp. 30-41. 
12. Alexy O., George G. (2013) Category divergence, straddling, and currency: Open innovation and the legitimation of illegitimate categories. Journal of Management Studies, vol. 50, no. 2, pp. 173-203.

13. Huang H.-C., Lai M.-C., Lin L.-H., Chen C.-T. (2013) Overcoming organizational inertia to strengthen business model innovation: An open innovation perspective. Journal of Organizational Change Management, vol. 26, no. 6, pp. 977-1002.

14. Kleemann F., Voss G.G., Rieder K. (2008) Un(der)paid innovators: The commercial utilization of consumer work through crowdsourcing. Science, Technology \& Innovation Studies, vol. 4, no. 1, pp. 5-26.

15. Becker A., Mladenow A., Kryvinska N., Strauss C. (2012) Aggregated survey of sustainable business models for agile mobile service delivery platforms. Journal of Service Science Research, vol. 4, no. 1, pp. 97-121.

16. Kopetzky R., Günther M., Kryvinska N., Mladenow A., Strauss C., Stummer C. (2013) Strategic management of disruptive technologies: a practical framework in the context of voice services and of computing towards the cloud. International Journal of Grid and Utility Computing, vol. 4, no. 1, pp. 47-59.

17. Bursuk I., Mladenow A., Novak N.M., Strauss C. (2016) Online cofounder search in tech startups. Proceedings of the 18th International Conference on Information Integration and Web-based Applications \& Services (iiWAS 2016). Singapore, 28-30 November 2016, pp. 482-488.

18. Andries P., Debackere K. (2013) Business model innovation: Propositions on the appropriateness of different learning approaches. Creativity and Innovation Management, vol. 22, no. 4, pp. 337358.

19. Gibson E., Jetter A. (2014) Towards a dynamic process for business model innovation: A review of the state-of-the-art. Proceedings of the Infrastructure and Service Integration Conference (PICMET 2014). Kanazawa, Japan, 27-31 July 2014, pp. 1230-1238.

20. Teece D.J. (2010) Business models, business strategy and innovation. Long Range Planning, vol. 43, no. 2-3, pp. 172-194.

21. Burr J., Guriksen S. (2012) Interactive pinball business. Proceedings of the 7th Nordic Conference on Human-Computer Interaction: Making Sense Through Design (NordiCHI 2012). Copenhagen, Denmark, 14-17 October 2012, pp. 129-138.

22. IAP2 (2014) IAP2's Public Participation Spectrum. Available at: https://www.iap2.org.au/Tenant/ C0000004/00000001/files/IAP2_Public_Participation_Spectrum.pdf (accessed 01 March 2017).

23. Chew E.K. (2016) iSIM: An integrated design method for commercializing service innovation. Information Systems Frontiers, vol. 18, no. 3, pp. 457-478.

24. Ebel P., Bretschneider U., Leimeister J.M. (2016) Leveraging virtual business model innovation. Information Systems Journal, vol. 26, no. 5, pp. 519-550.

25. Ogilvie T. (2015) How to thrive in the era of collaborative services entrepreneurship. Research Technology Management, vol. 58, no. 5, pp. 24-33.

26. Trimi S., Berbegal-Mirabent J. (2012) Business model innovation in entrepreneurship. International Entrepreneurship and Management Journal, vol. 8, no. 4, pp. 449-465.

27. Berre A.J., Man H.D., Lew Y., Elvesaeter B., Ursin-Holm B.M. (2013) Open business model, process and service innovation with VDML and ServiceML. Proceedings of 5th International IFIP Working Conference on Enterprise Interoperability (IWEI 2013). Enschede, The Netherlands, 27-28 March 2013, pp. 127-142.

28. Zolnowski A., Weiss C., Bohmann T. (2014) Representing service business models with the service business model canvas: The case of a mobile payment service in the retail industry. Proceedings of the 47th Hawaii International Conference on System Science (HICSS 2014). Hawaii Big Island, 6-9 January 2014, pp. 718-727.

29. Pynnönen M., Hallikas J., Ritala P. (2012) Managing customer-driven business model innovation. International Journal of Innovation Management, vol. 16, no. 4, pp. 1-13. 
30. Mladenow A., Bauer C., Strauss C. (2016) Crowd logistics: the contribution of social crowds in logistics activities. International Journal of Web Information Systems, vol. 12, no. 3, pp. 379-396.

31. Ernst C., Mladenow A., Strauss C. (2017) Collaboration and crowdsourcing in emergency management. International Journal of Pervasive Computing and Communications, vol. 13, no. 2, pp. 176-193.

32. Gudiksen S. (2015) Business model design games: Rules and procedures to challenge assumptions and elicit surprises. Creativity and Innovation Management, vol. 24, no. 2, pp. 307-322.

33. Denicolai S., Ramirez M., Tidd J. (2014) Creating and capturing value from external knowledge: the moderating role of knowledge intensity. $R \& D$ Management, vol. 44, no. 3, pp. 248-264. 